\title{
Surgical Management of Pyogenic Discitis of Lumbar Region
}

\author{
Pramod Devkota ${ }^{1}$, Krishnakumar $\mathrm{R}^{2}$, Renjith Kumar J ${ }^{2}$ \\ ${ }^{1}$ Department of Orthopaedics and Trauma Surgery, Gandaki Medical College Teaching Hospital, Pokhara, Nepal \\ ${ }^{2}$ Division of Spine and Musculoskeletal Oncology, Department of Orthopaedics and Trauma Surgery, Amrita Institute of Medical Sciences, Cochin, \\ Kerala, India
}

Study Design: Retrospective review of patients who had pyogenic discitis and were managed surgically.

Purpose: To analyze the bacteriology, pathology, management and outcome of pyogenic discitis of the lumbar region treated surgically.

Overview of Literature: Surgical management of pyogenic discitis is still an infrequently used modality of treatment.

Methods: A total of 42 patients comprised of 33 males and 9 females who had pyogenic discitis with a mean age of 51.61 years (range, 16-75 years) were included in this study. All the cases were confirmed as having pyogenic discitis by pus culture report and histopathological examination. The mean follow-up period was 41.9 months.

Results: Debridement and posterior lumbar interbody fusion with autologous iliac bone graft was done in all cases. Thirteen (30.95\%) patients had other medical co-morbidities. Five cases had a previous operation of the spine, and three cases had a history of vertebral fracture. Three patients were operated for gynaecological problems, and four cases had a history of urological surgery. L4-5 level was the most frequent site of pyogenic discitis. The most common bacterium isolated was Staphylococcus aureus (S. aureus). Radiologically good fusion was seen in the majority of patients.

Conclusions: Pyogenic discitis should be suspected in people having pain and local tenderness in the spinal region with a rise in inflammatory parameters in blood. The most common bacterium was $S$. aureus, but there were still a greater number of patients infected with other types of bacteria. Therefore, antibiotics therapy should be started only after isolating the bacteria and making the culture sensitivity report.

Keywords: Pyogenic; Infection; Discitis; Antibiotics

\section{Introduction}

Pyogenic spinal infection is an uncommon disorder encompassing a broad spectrum of diseases including septic spondylodiscitis, osteomyelitis, epidural and paravertebral abscess formation. Presentation can be vague and highly variable but usually includes back pain and fever. The condition is often recognized and treated too late [1]. Spondylodiscitis is an infection of the intervertebral disc space and vertebral bodies. It can be a serious disease because of diagnostic delay and inadequate treatment [2].

Management of pyogenic spinal infection can involve conservative methods and surgical intervention [3]. Surgical management is usually indicated for patients in whom medical management of the disease has failed; or those with progressive neurological compromise, spinal instability and deformity due to significant endplate and vertebral destruction or intractable pain. Surgery for

Received Dec 11, 2012; Revised Jun 29, 2013; Accepted Jun 29, 2013

Corresponding author: Pramod Devkota

Department of Orthopaedics and Trauma Surgery, Gandaki Medical College Teaching Hospital,

Sanchayakosh Bhawan, Naya Bazaar, Nepal

Tel: +(97761)538595, Fax: +(97761)550254, E-mail:pramodcd@yahoo.com 
spondylodiscitis includes debridement of affected tissue, neural decompression, ventral vertebral body reconstruction, and spinal stabilization [4]. We present our experience of surgical management of pyogenic discitis dorsolumbar and lumbosacral region by posterior lumbar inter-body fusion (PLIF).

\section{Materials and Methods}

This retrospective study was done at the Departments of Orthopaedics, Spine Surgery division of Amrita Institute of Medical Sciences, Kochi, Kerala, India. From January 2001 to December 2009, the medical records of 42 cases were reviewed who were diagnosed provisionally for spondylodiscitis by physical examination, X-ray and magnetic resonance imaging (MRI) report, and laboratory findings. All cases were confirmed of having pyogenic discitis by infected material culture report and histopathological examination. Patients with tuberculosis or fungal discitis and those managed by non-surgical methods were excluded from the study. Clinical presentations, bacteriology, haematology, and predisposing factors were analyzed.

Surgical treatment consisted of thorough removal of infected, necrotic tissue with extensive irrigation. Debridement and PLIF with autologous bone grafting was done using iliac crest bone (Figs. 1, 2).
The mean follow-up period was 41.9 months, with a range from 24 to 63 months. Thirteen patients (30.95\%) had other co-morbidities like diabetes mellitus (DM), hypertension (HTN), renal failure, chronic obstructive pulmonary disease (COPD), heart diseases, and malig-
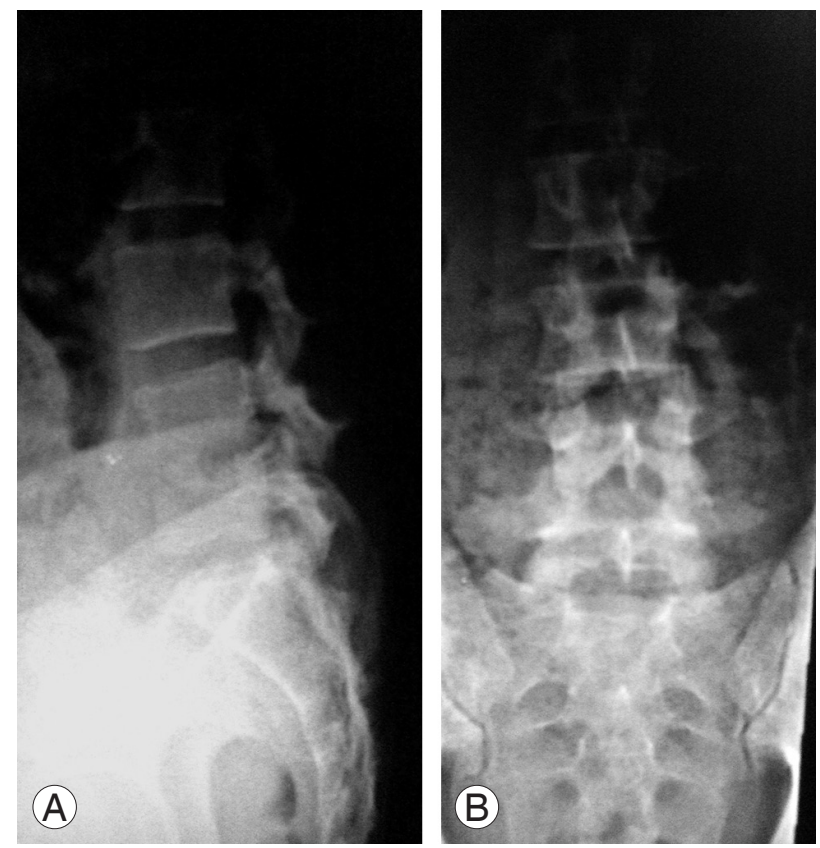

Fig. 1. (A, B) anteroposterior and lateral views of a 44-year-old-male with L4-L5 spondylodiscitis.
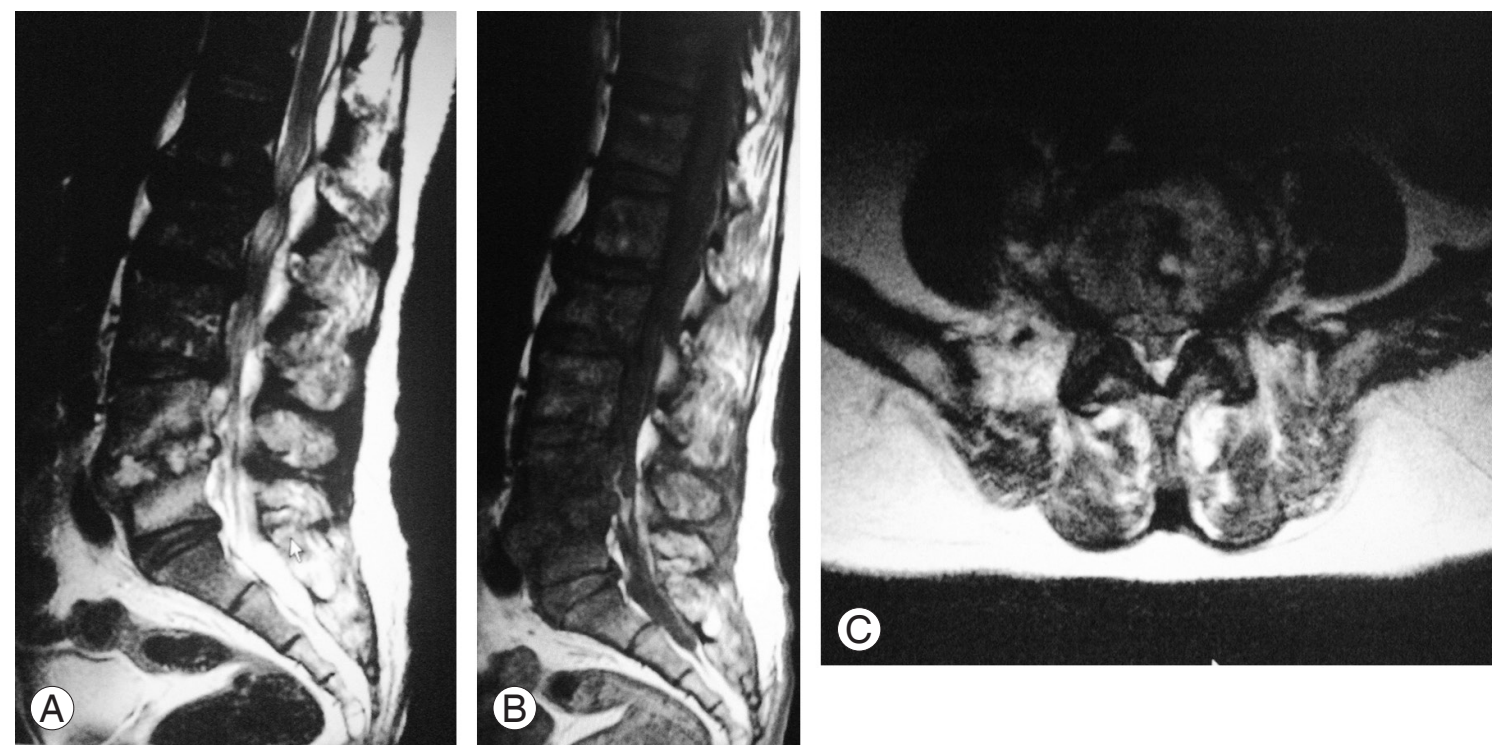

Fig. 2. Magnetic resonance imaging (MRI) of the same patient showing destruction of the L4-L5 intervertebral disc. (A) Sagital MRI T2 Image, (B) Sagital MRI T1 Image, and (C) Axial MRI Image. 
nancies. Five cases (11.9\%) had a previous operation in the spinal region, and three (7.14\%) cases had a history of previous vertebral fracture. Three patients (7.14\%) were operated for gynaecological problems, and four cases $(9.52 \%)$ had a history of urological surgery.

\section{Results}

There were 33 male and 9 female patients, and their ages ranged from 16 to 75 years with the mean age being 51.61 years (Table 1).

The most frequent manifestations were local pain on the affected site in 37 cases $(88.05 \%)$, and 23 patients (54.76\%) also had a general systemic illness of low grade fever and weight loss. Thirteen patients (30.95\%) had comorbidities like renal failure, heart disease, rheumatoid arthritis, HTN, COPD, DM, and multiple organ failure.

Raised erythrocyte sedimentation rate (ESR), Creactive protein (CRP) and rise in total white blood cell (WBC) count were the most frequent inflammatory markers in all cases. Preoperatively, the mean WBC was $(17.66 \pm 2.93) \times 10^{9} / \mathrm{L}$, ESR was $73.69 \pm 13.16 \mathrm{~mm} / \mathrm{hr}$, and CRP was $40.08 \pm 10.21 \mathrm{mg} / \mathrm{L}$. The most common level of infection was L4-5 (19 cases, 45.24\%), followed by L3-4 (8 cases, 19.05\%), D12-L1 (6 cases, 14.28\%), L5-S1 (5 cases, $11.91 \%)$, L1-L2 (2 cases, $4.76 \%)$ and L2-L3 (2 cases, $4.76 \%)$. In all cases bacteria were isolated and histopathology examination also confirmed the pyogenic discitis. The most common bacterium isolated was Staphylococcus aureus (S. aureus) in 19 cases (45.24\%), followed by Escherichia coli (E. coli, 7 cases, 16.65\%), Klebseila pneuomonae (6 cases, 14.29\%), Pseudomonous seroginosa, Enterobacter species, and Staphyloccus pneumonia. Two cases $(4.76 \%)$ were identified as methilicillin resistant Staphylococcus aureus (MRSA). All patients were given intravenous antibiotics of first generation cephalosporin before the results of the bacteria and sensitivity test. The details of bacteria are in Table 2 .

Intravenous antibiotics were given for four weeks followed by four weeks of oral antibiotics based on the drug sensitivity report. All patients were evaluated through laboratory tests, local examination and X-rays. CRP, ESR level and leukocyte counts decreased in all cases after the treatment at eight weeks, showing the mean WBC of $(8.92 \pm 1.37) \times 10^{9} / \mathrm{L}$, ESR of $18.59 \pm 8.63 \mathrm{~mm} / \mathrm{hr}$, and CRP of $9.3 \pm 2.9 \mathrm{mg} / \mathrm{L}$. Symptoms like pain and local tenderness were significantly decreased in 31 cases $(73.81 \%)$ with clear improvement in the visual analogue scale score; better improvement was noted in seven cases (16.67\%); no improvement was noted in four cases $(9.52 \%)$. Four (9.52\%) patients succumbed after the operation to their coexisting diseases.

Statistical analysis of preoperative values and postoperative values of TC, ESR, and CRP by the paired t-test showed $p<0.001$ (significant). Radiologically, fusion was assessed by modified Lee's [5] criteria and revealed definitive fusion in 23 cases (54.76\%), probable fusion in ten cases $(23.81 \%)$, possible pseudoarthrosis in five cases $(11.91 \%)$ and definite pseudoarthrosis in four cases (9.54\%) (Fig. 3).

\section{Discussion}

The diagnosis of spondylodiscitis should be considered in patients presenting with insidious onset of progressive, severe back or neck pain associated with fever and other systemic symptoms like progressive motor weakness and radiating pain to limbs. Patients of advanced age, with DM, who are immune compromised, or who have undergone surgery or have an established focus of infection must be viewed with a high index of suspicion [4]. Well known pathophysiological mechanisms of spondylodis-
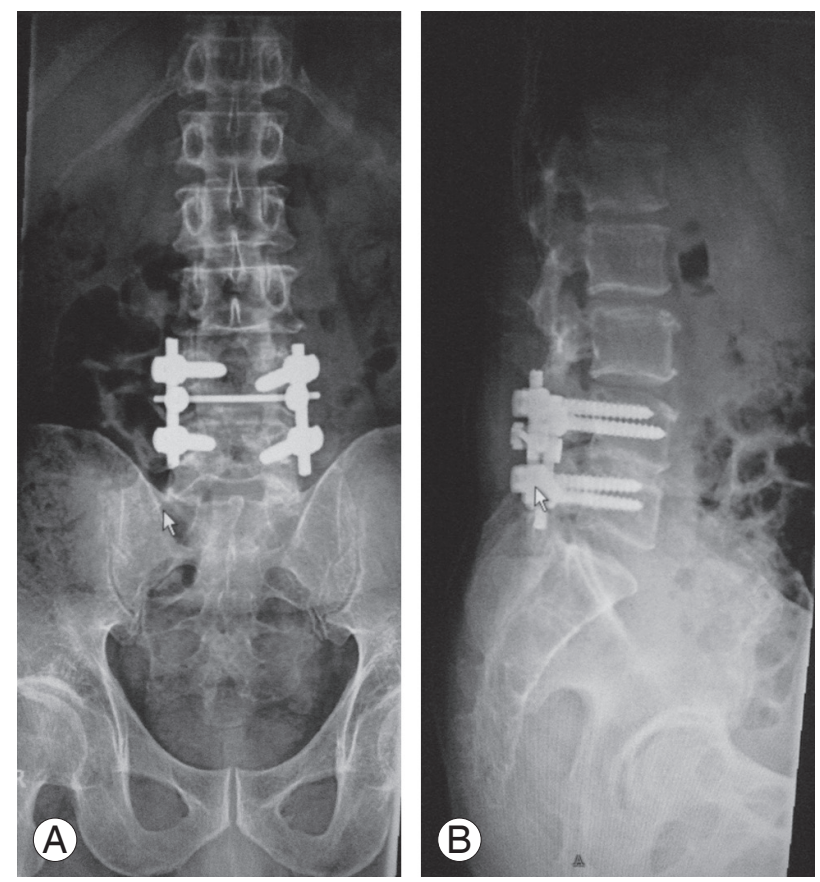

Fig. 3. (A, B) Good fusion is seen after posterior lumbar inter-body fusion between $\mathrm{L} 4$ and $\mathrm{L} 5$ level. 
Table 1. The detail of the patient profile

\begin{tabular}{|c|c|c|c|}
\hline Age (yr) & Sex & Level involved & Co-morbodities/associated complications \\
\hline 44 & M & L4-5 & - \\
\hline 45 & M & L3-4 & - \\
\hline 38 & M & L2-3 & - \\
\hline 45 & $\mathrm{~F}$ & L3-4 & - \\
\hline 51 & M & $\llcorner 4-5$ & - \\
\hline 37 & M & D12-L1 & - \\
\hline 45 & $\mathrm{~F}$ & Ł3-4 & - \\
\hline 57 & M & L3-4 & Heart disease, diabetes mellitus \\
\hline 46 & M & $\llcorner 4-5$ & - \\
\hline 62 & $\mathrm{~F}$ & L5-S1 & Renal failure, hypertension \\
\hline 64 & M & $\mathrm{L} 1-2$ & Diabetes mellitus, hypertension, renal failure \\
\hline 55 & M & $\mathrm{L} 1-2$ & Diabetes mellitus, hypertension, renal failure \\
\hline 34 & M & $\lfloor 4-5$ & - \\
\hline 41 & M & L4-5 & - \\
\hline 50 & M & $\llcorner 4-5$ & - \\
\hline 16 & M & L5-S1 & - \\
\hline 58 & M & L3-4 & Diabetes mellitus, hypertension coronary artery disease \\
\hline 64 & M & L4-5 & Chronic obstructive pulmonary disease hypertension \\
\hline 60 & M & L4-5 & - \\
\hline 50 & M & L5-S1 & - \\
\hline 46 & M & L3-4 & - \\
\hline 59 & M & D12-L1 & - \\
\hline 57 & M & D12-L1 & - \\
\hline 56 & M & L4-5 & - \\
\hline 27 & M & $\llcorner 4-5$ & - \\
\hline 52 & M & L2-3 & - \\
\hline 19 & $\mathrm{~F}$ & $\lfloor 4-5$ & - \\
\hline 60 & M & D12-L1 & - \\
\hline 56 & M & $\lfloor 4-5$ & - \\
\hline 29 & $\mathrm{~F}$ & L4-5 & - \\
\hline 75 & $\mathrm{~F}$ & D12-L1 & Malignancy, diabetes mellitus \\
\hline 64 & M & D12-L1 & Renal failure, chronic obstructive pulmonary disease \\
\hline 70 & M & $\lfloor 4-5$ & - \\
\hline 62 & M & L4-5 & Diabetes mellitus, hypertension \\
\hline 55 & $\mathrm{~F}$ & L3-4 & - \\
\hline 60 & $\mathrm{~F}$ & $\lfloor 4-5$ & - \\
\hline 62 & M & L3-4 & - \\
\hline 62 & M & L4-5 & - \\
\hline 59 & M & L4-5 & Diabetes mellitus, hypertension, chronic obstructive pulmonary disease \\
\hline 64 & M & L5-S1 & Diabetes mellitus, chronic obstructive pulmonary disease \\
\hline 57 & $\mathrm{~F}$ & L5-S1 & Renal failure, vasculitis \\
\hline 55 & M & L4-5 & Diabetes mellitus, hypertension, chronic obstructive pulmonary disease \\
\hline
\end{tabular}


Table 2. The bacterial characteristics

\begin{tabular}{lc}
\multicolumn{1}{c}{ Bacteria } & No. of patients (\%) \\
\hline Staphylococcus aureus & $19(45.24)$ \\
\hline Eschericia coli & $7(16.65)$ \\
\hline Klepseilla pneumoniae & $6(14.29)$ \\
\hline Pseudomonous aeroginosa & $3(7.15)$ \\
Enterobacter spec & $3(7.15)$ \\
Staphyloccus pneumonia & $2(4.76)$ \\
Methilicillin resistant Staphylococcus & $2(4.76)$ \\
\hline aureus & \\
\hline
\end{tabular}

citis are hematogenous spread of microbial organism into the richly vascularized vertebral metaphyses or through paraspinous venous plexus secondary [6]. The genitourinary tract, upper respiratory tract, oral cavity, cutaneous ulcer, traumatic wounds and other surgical sites are also some of the common sources of infection [7].

Most patients presented in this study had local pain and tenderness with a rise in inflammatory parameters like ESR, CRP in the haematological study as reported in the literature [8]. The incidence of pyogenic spondylodiscitis is around 1:250,000, which represents around 3\% to $5 \%$ of osteomyelitis as a whole [2]. Ten to 15 percentages of all vertebral infections can be ascribed to exogenous spondylodiscitis, with $S$. aureus, as the most common pathogen (about $30 \%-80 \%$ ), $2 \%$ to $16 \%$ of which are reported to be MRSA, followed by gram negative E. coli which accounts for $5 \%$ to $30 \%[9,10]$. The most common organism in our study was also $S$. aureus which accounted for about 45.24\%; gram negative E. coli accounted for $16.65 \%$ and MRSA was found in $4.76 \%$ of the cases. However, other bacteria were also found, forming more than $50 \%$ of spinal infection cases. This shows the need for isolation of bacteria and drug sensitivity test for the successful treatment of the disease.

In this study, the most common site of infection was L4-L5 level followed by L3-L4, D12-L1, L5-S1, L1L2, and L2-L3. Lim et al. [4] also found L4-L5 to be the most common site of infection, and he believed that this is because of a relatively large vertebral body and disc space.

Imaging examination consists of plain radiographs, MRI, and computed tomography scans [11]. Plain radiographs generally demonstrate distinct endplate erosions suggestive of infection. MRI exhibits high sensitivity in the early identification of spondylodiscitis in all patients; MRI also clearly demonstrates the presence and location of any retropharyngeal, paravertebral, psoas and epidural abscess [11]. In this series of patients, who were suspected of having pyogenic discitis based on their clinical symptoms and plain X-ray findings, were advised to undergo MRI for further evaluation, making MRI the major diagnostic tool for the diagnosis of spondylodiscitis.

There are some controversies on operative or conservative treatment of spondylodiscitis despite modern medical management with antibiotics $[12,13]$. Conservative medical management in these patients is usually accompanied by a long period of immobilization as well as incomplete bony fusion. If bone destruction exists, the rate of pseudoarthrosis and instability is can be as high as $50 \%$ [14]. Most of the patients in this study were managed by surgical intervention. Indications for surgical treatment were: failed medical management, spinal instability or developing deformity, significant disc destruction, neurological deficit and intractable pain. Debridement and stabilization are warranted for the treatment of non-tuberculous spondylodiscitis in cases of neurological compromise, deformity, instability, abscess formation, extensive destruction, intractable pain or failure of medical management [15].

Debridement and instrumentations were performed in all cases of this study for instability due to disc and bone destruction and erosion. Instrumentation after debridement has gained wide acceptance in the setting of concomitant infection. Several retrospective studies revealed greater improvement in patients with posterior instrumentation than in those without instrumentation $[16,17]$.

In all cases of this series, appropriate antibiotics in reference to sensitivity were administrated, and improvement was noted. However, the death of four patients was due to the other severe systemic illnesses. GarciaBordes et al. [18] believed that microbiology and MRI are vital components in the diagnosis of pyogenic discitis and surgical decompression with appropriate antibiotic regimen is the method for favourable outcome. Bacteria isolates were varied in our study, even though $S$. aureus was determined as the most common one. There were even a greater number of patients with other isolates. This proves the importance of obtaining bacterial culture before initiating antibiotic therapy. 


\section{Conclusions}

Diagnosis of pyogenic spondylodiscitis could be challenging and commonly missed. Pyogenic discitis should be suspected in patients with local pain and tenderness followed by systemic illness such as low grade fever with a rise in inflammatory parameters in the haematology report. Although the most common bacterium for pyogenic discitis was $S$. aureus but there was still a greater number of patients infected by other types of bacteria. Therefore, antibiotics therapy should be started only after obtaining laboratory evidence of the involved bacteria and drug sensitivity.

\section{Conflict of Interest}

No potential conflict of interest relevant to this article was reported.

\section{References}

1. White SH, Dickson S, Colman T, Hoque F, Boos CJ. Back pain in a Bangladeshi worker in Iraq. J R Army Med Corps 2010;156:44-6.

2. Yemisci OU, Cosar SN, Oztop P, Karatas M. Spondylodiscitis associated with multiple level involvement and negative microbiological tests: an unusual case. Spine (Phila Pa 1976) 2010;35:E1006-9.

3. Butler JS, Shelly MJ, Timlin M, Powderly WG, O'Byrne JM. Nontuberculous pyogenic spinal infection in adults: a 12-year experience from a tertiary referral center. Spine (Phila Pa 1976) 2006;31:2695700 .

4. Lim JK, Kim SM, Jo DJ, Lee TO. Anterior interbody grafting and instrumentation for advanced spondylodiscitis. J Korean Neurosurg Soc 2008;43:5-10.

5. Lee CK, Vessa P, Lee JK. Chronic disabling low back pain syndrome caused by internal disc derangements. The results of disc excision and posterior lumbar interbody fusion. Spine (Phila Pa 1976) 1995;20:35661.

6. Mann S, Schutze M, Sola S, Piek J. Nonspecific pyogenic spondylodiscitis: clinical manifestations, surgical treatment, and outcome in 24 patients. Neurosurg Focus 2004;17:E3.
7. Osenbach RK, Hitchon PW, Menezes AH. Diagnosis and management of pyogenic vertebral osteomyelitis in adults. Surg Neurol 1990;33:266-75.

8. Sobottke R, Seifert H, Fatkenheuer G, Schmidt M, Gossmann A, Eysel P. Current diagnosis and treatment of spondylodiscitis. Dtsch Arztebl Int 2008;105:181-7.

9. Sapico FL. Microbiology and antimicrobial therapy of spinal infections. Orthop Clin North Am 1996;27:913.

10. Nolla JM, Ariza J, Gomez-Vaquero C, et al. Spontaneous pyogenic vertebral osteomyelitis in nondrug users. Semin Arthritis Rheum 2002;31:271-8.

11. Modic MT, Masaryk T, Paushter D. Magnetic resonance imaging of the spine. Radiol Clin North Am 1986;24:229-45.

12. Lehovsky J. Pyogenic vertebral osteomyelitis/disc infection. Baillieres Best Pract Res Clin Rheumatol 1999;13:59-75.

13. Przybylski GJ, Sharan AD. Single-stage autogenous bone grafting and internal fixation in the surgical management of pyogenic discitis and vertebral osteomyelitis. J Neurosurg 2001;94:1-7.

14. Eysel P, Hopf C, Vogel I, Rompe JD. Primary stable anterior instrumentation or dorsoventral spondylodesis in spondylodiscitis? Results of a comparative study. Eur Spine J 1997;6:152-7.

15. Ozalay M, Sahin O, Derincek A, Onay U, Turunc T, Uysal M. Non-tuberculous thoracic and lumbar spondylodiscitis: single-stage anterior debridement and reconstruction, combined with posterior instrumentation and grafting. Acta Orthop Belg 2010;76:100-6.

16. Hee HT, Majd ME, Holt RT, Pienkowski D. Better treatment of vertebral osteomyelitis using posterior stabilization and titanium mesh cages. J Spinal Disord Tech 2002;15:149-56.

17. Liljenqvist U, Lerner T, Bullmann V, Hackenberg L, Halm H, Winkelmann W. Titanium cages in the surgical treatment of severe vertebral osteomyelitis. Eur Spine J 2003;12:606-12.

18. Garcia-Bordes L, Aguilera-Repiso JA, Serfaty-Soler JC, et al. An unusual case of spondylodiscitis. Spine (Phila Pa 1976) 2010;35:E167-71. 